\section{The Solar Prominences}

IT may interest some of your readers to hear that the bright lines of the hydrogen "flames" extending beyond the sun's disc can be seen with much less instrumental aid than has hitherto been considered indispensable. I have succeeded in seeing them quite unmistakably by the following very simple means. I fixed one of Mr. Browning's direct vision spectroscopes (having seven prisms) on a board which also carried a two-inch object-glass belonging to a good field telescope. I mounted the instrument thus arranged (shall I say as an altazimuth) on the back of an ordinary bed-room mirror, and directed it at the sun. The slit was set so as nicely to divide the $D$ line, and a blue glass was generally interposed in front of the slit to sift the light. As the image of the sum traversed the slit at intervals, the flames appeared as bright prolongations of the F line extending beyond the sun's limb. It was also clearly seen at times that these prolongations were narrower than the $F$ line and were not in the centre of it, also that they were frequently detached from the sun's limb, and sometimes they were not straight: appearances depending as is gerierally supposed on the velocity and pressure of the gas in the flame. The flames were also readily seen in the $C$ line. In observing the solar spectrum I have found coloured glasses in front of the slit very useful to shut out as much as possible of the light from the parts of the spectrum not under observation. By using the spectroscope without its slit and collimating lens, and directing it towards the great nebula in Orion, it shows close together three bright images of the nebula exhibited on a continuous spectrum.

Streatham Hill, April 8.

ERNEST CARPMAEL

\section{Modern Geometry and the University of London}

THE letter entitled "Euclid as a Text-book," which appeared in last week's NATURE, seems to me to call for immediate reply. Many students about to present themselwes for examination at the University of London and other places during the next year have been told by their tutors that a thorough and accurate knowledge of geometry would be better appreciated than the power to make verbal transcriptions of Euclid; and the letter referred to is calculated to shake the confidence of such students in the method they have been advised to pursue, and to produce a feeling of uncertainty as to the way in which demonstrations differing from Euclid's will be received by the examiners. But I think that an inspection of the calendars will re-assure them, and show that they have no cause to fear the result of examination, especially when the University of London is the examining body.

The papers consist of certain propositions common to Euclid and modern text-books, and a number of problems readily solved by a student of modern geometry, but almost impossible to one who has simply committed to memory Euclid's text. My own strong conviction is, that the latter would find some difficulty in passing the recent examinations. The questions given fall strictly within the University programme, and treat of important properties of geometrical figures which no student possessing a knowledge of approved modern methods could possibly be ignorant of. The "alternative" or modern side has been carefully kept in view and placed on a footing of equality with the ancient system.

During the year 1869 eight of my pupils who had not read Euclid were candidates for matriculation ; all passed, and none were placed lower than the first class; so that I cannot see the advisability of boys returning to Euclid "in order that their prospect of good places may be enhanced."

Mr. Tucker apparently clesires a series of questions which could only be answered on modern principles. This would amount to a system of protection, and could not fail to be objectionable.

The student of the New Geometry has, in fact, a great advantage. To the.learner of Euclid a fact clothed in terms slightly varying from Euclid's is often new and startling, but to the modern student who learns every proposition in its most general form and assimilates the idea apart from the external or verbal form in which it may accidentally be presented, it is already familiar and trite. The statement that a change in the London syllabus has been or will be made "as a sop to Cerberus," will strike many as singularly infelicitous and ungenerous. The Senate of the University does not say one thing and mean another; it has always shown unflinching courage in the reform of English methods of education, legislating as an initiator rather than as a follower. The tendency of the University throughout its existence has been to discourage cramming in every shape and form, in the teeth of numerous difficulties and influences to which the term "obstructive" rightly applies rather than to the University itself. It is to be regretted that a letter dating from University College School should show so little confidence in the intrinsic superiority of modern methods, and still more that it should impeach the integrity of men who have not so deserved.

Brixton, March 28

RICHARD WORMELI

\section{DEATH OF PROFESSOR MAGNUS}

$\mathrm{N}$ the 4 th of April, I870, at a quarter-past Io p.m., died peacefully, after a long illness, Dr. Gustav Magnus, Professor of Physics, and Director of the Physical Cabinet in the University of Berlin. He was an experimental philosopher of great and varied excellence, executing his work with the choicest apparatus and with the most conscientious care. His numerous labours are known to all students of physics, and they are such as to secure for him an enduring fame. On the 28 th of April, I85I, I first saw Professor Magnus on his own doorstep in Berlin. His aspect won my immediate regard, which was strengthened to affection by our subsequent intercourse. He gave me a working place in his laboratory, and it was there I carried out the investigation on Diamagnetism and Magne-crystallic Action, which is published in the Philosophical Magazine for Sept. $185 \mathrm{I}$. In $1853 \mathrm{I}$ was again in Berlin, and found under his roof the same ready help and sympathy. Professor Hirst and myself paid him a visit last summer; and he afterwards attended the Exeter Meeting of the British Association, where his frank, genial, and gentlemanly demeanour were conspicuous to all. Over and above his direct contributions to Science, Prof. Magnus exercised a powerful indirect influence, through the kindly aid and countenance which he lent to young inquirers. When I bade him good-bye in I85I his last words to me were, "If you should meet any really able young fellow, willing to work, and to whom such assistance as I can render would be valuable, send him to me." There are many such, now no longer young, who, like myself, will mingle a grateful memory of his goodness with their grief for his loss.

Royal Institution, I Ith April

JOHN TYNDALL

\section{THE SOURCES OF THE NILE*}

THE main point of interest in the latest travels of Livingstone, and that which gives to them a distinctive importance over the great accomplishments of his former journeys, is, that in these, Livingstone has undoubtedly visited and beheld the long-sought-for sources of the Nile. It is true that there still remains considerable doubt as to which of the basins that he has explored will ultimately be acknowledged as the cradle of the Nile, but this at least is certain, that the real head streams have been seen by him, and the vexed question has by these explorations resolved itself into a choice between two or perhaps three streams. Livingstone himself has apparently no bias in favour of one or other so that the discussion is a perfectly open one. The three rival head streams are, first, the feeders of Lake Liemba, and second the Chambeze River and its lake chain, both of which rise near the eastern edge of the great longitudinal plateau of the side of Africa next the Indian Ocean; the third is the source recently claimed for the Nile by

* An abstract of part of a paper read before the Royal Society of Edinburgh, March 21st. 